\title{
Control of DC Motor Using Integral State Feedback and Comparison with PID: Simulation and Arduino Implementation
}

\author{
Alfian Ma'arif*, Naufal Rahmat Setiawan \\ Department of Electrical Engineering, Universitas Ahmad Dahlan, Yogyakarta, Indonesia \\ Email: alfianmaarif@ee.uad.ac.id \\ *Corresponding Author
}

\begin{abstract}
The Direct Current (DC) motor is widely applied in various implementations. The main problem in the DC motor is controlling the angular speed on the specific reference. This research then proposed an integral state feedback design for tracking control in DC motor, with Simulink Matlab simulation and the Arduino hardware implementation. The results will be compared with the implementation of the PID controller. The integral state feedback controller can handle the system to reach the setpoint with good performance in the simulations, even with changing different poles and setpoints. In the hardware implementation, the current sensor (INA219) and encoder sensor are used since all state variables need to be calculated. Based on the result, the controller can reach the setpoint stably with oscillation. Similar results are showed in simulations with different setpoints. Compared with the PID Controller, the integral state feedback controller has a better response with faster rise time and faster settling time.
\end{abstract}

Keywords-DC motor, Arduino, Integral State Feedback, Angular Speed, PID Controller

\section{INTRODUCTION}

A Direct Current (DC) motor is a device that converts electrical power to mechanical power. DC motor also has many types such as brushed DC Motor [1], servo motor [2], stepper [3], and Brushless DC (BLDC) Motor [4]. Its applications are widely varied, such as balancing robot [5][6], line follower robot [7][8], maze solving robot [9], pendulum [10], Furuta pendulum [11], and electric vehicles [12][13]. It is more popular than AC motors because it has low power, good performance [14], and easy-to-control characteristics [15].

The main problem in DC motor is controlling the angular speed on the specific reference, even with uncertainty or disturbance happens [16][17]. The angular speed can be controlled by adjusting the motor's power supply. It sounds simple, yet is very challenging considering the whole system's performance. Thus, a controller is needed.

Some controllers can be implemented to the DC motor. PI Controller [18], PID Controller [19][20], ANFIS Based Hybrid P-I-D Controller [21], Fractional Order PID [22], Fuzzy Logic Controller [23], Model Reference Adaptive Control (MRAC) [24], Integral state feedback [25], have been implemented to DC motor system. The most popular among them is the PID controller since it is quite simple and easy to be implemented in a real hardware system [26][27][28]. Those previously mentioned researches were done only in the simulation since the real hardware system's implementation is difficult to be done.

However, the PID Controller also has some weaknesses. Any slightest change in setpoint will affect the whole system's performance. Hence, it is not suitable to use the PID controller for tracking control in the DC motor.

The alternative of a controller with simple and easy-todesign characteristics for tracking control in DC motor is the integral state feedback. Integral state feedback has been implemented in many systems such as PMSM [29][30][31], AC Induction Motors [32], Micro positioner [33], Level Control of two tank System [34], Quadcopter [35], magnetic levitation system [36][37], Boost Converter [38], buck converter [39], Flyback converter [40], DC-DC Converter [41], inverted pendulum [42], [43] wireless power transfer [44] and inverter [45]. The integral state feedback has some advantage such as simple structure, easy to design, it can be implemented in a multi-input multi-output system, and it has good performance [46][47].

However, the hardware implementation of integral state feedback is very challenging because all state variables in the system need to be calculated. This research then proposed an integral state feedback design for tracking control in DC motor, with Simulink Matlab simulation and Arduino hardware system implementation. The results of the system's responses will be compared with the implementation of the PID controller [48].

The research is written as follows. The first section is the introduction. The second section is the method that consists of the DC Motor Modelling, Integral State Feedback Control, and Hardware Implementation Configuration. The third section is the result and discussion that consists of Simulink Matlab Simulation Result, Hardware Implementation Result, and Comparison with PID Controller. The last section is the conclusions.

\section{METHODS}

\section{A. DC Motor Model}

Some modeling methods to determine the DC motor model are the physical and identification system models [49]. It can be determined in transfer function or state-space representation. 
The state-space model of the DC motor model can be made through mechanical and electrical analysis. The torque (T) generated by the DC motor is

$$
T=K_{t} i
$$

where, $K_{t}$ is the constant factor, $i$ is the armature current.

The back-EMF is

$$
e=K_{e} \dot{\theta}
$$

where, $K_{e}$ is the constant factor.

The torque constant and back-EMF constant have the same unit as $K_{t}=K_{e}$. Thus, $K$ will be used to represent them. The DC motor can be modeled then by using the second newton's law and Kirchhoff voltage law as

$$
\begin{gathered}
J \ddot{\theta}+b \dot{\theta}=K i \\
L \frac{d i}{d t}+R i=V-K \dot{\theta}
\end{gathered}
$$

where $J$ is moment inertia, $R$ is the resistance, $L$ is the inductance, $b$ is the friction constant.

The DC motor model can be written in the state-space form as

$$
\begin{gathered}
\frac{d}{d t}\left[\begin{array}{c}
\dot{\theta} \\
i
\end{array}\right]=\left[\begin{array}{cc}
-\frac{b}{j} & \frac{K}{J} \\
-\frac{K}{L} & -\frac{R}{L}
\end{array}\right]\left[\begin{array}{c}
\dot{\theta} \\
i
\end{array}\right]+\left[\begin{array}{l}
0 \\
1 \\
\frac{L}{L}
\end{array}\right] u \\
y=\left[\begin{array}{ll}
\dot{\theta} & i
\end{array}\right] x
\end{gathered}
$$

Define the $x_{1}$ as the angular speed, $x_{2}$ as the current. Hence, the state-space model can be written as

$$
\begin{gathered}
\dot{x}=A x+B u \\
y=C x
\end{gathered}
$$

where

$$
x=\left[\begin{array}{l}
x_{1} \\
x_{2}
\end{array}\right] \quad A=\left[\begin{array}{cc}
-\frac{b}{J} & \frac{K}{J} \\
-\frac{K}{L} & -\frac{R}{L}
\end{array}\right] \quad B=\left[\begin{array}{l}
0 \\
\frac{1}{L}
\end{array}\right] C=\left[\begin{array}{ll}
1 & 0
\end{array}\right]
$$

\section{B. Integral State Feedback}

The integral state feedback controller has other names: full state-feedback [50][51], servo state feedback [52][53][54], servo controller [32][55][56][57], or statefeedback integral [39]. The scheme is shown in Figure 1. It consists of the integral control $u_{I}$ and the state feedback control $u_{S F}$.

The equation can be written as

$$
\begin{gathered}
x=A x+B u \\
y=C x \\
u=u_{I}+u_{S F}=e k_{I}-K x \\
\dot{e}=r-y=r-C x \\
e=\int \dot{e} d t
\end{gathered}
$$

where $x$ is the state vector of the plant, $e$ is the output of integrator, $\dot{e}$ is the deviation between the reference and the feedback, $u$ is the control signal, $y$ is the output signal, $r$ is the reference signal, $k_{I}$ is the integral parameter constant, $K$ is the state feedback constant, $A$ is the constant matrix, $B$ is the constant matrix, and $C$ is the constant matrix.

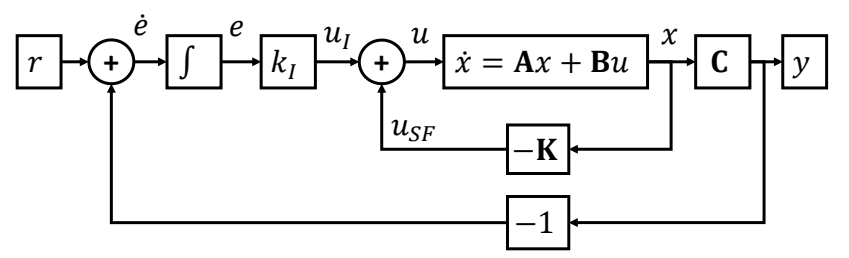

Fig. 1. System Block Diagram

In the integral state feedback, all of the system state variables must be known. Thus, it needs sensors for calculating the unknown states. Else, the observer can be used as an alternative.

\section{Hardware System Design}

The system structure design to control the DC motor using the integral state feedback is shown in Figure 2. There are some components such as an encoder to calculate the angular speed, the current sensor to calculate the current, Arduino as the microcontroller, and a motor driver to drive the motor supply.

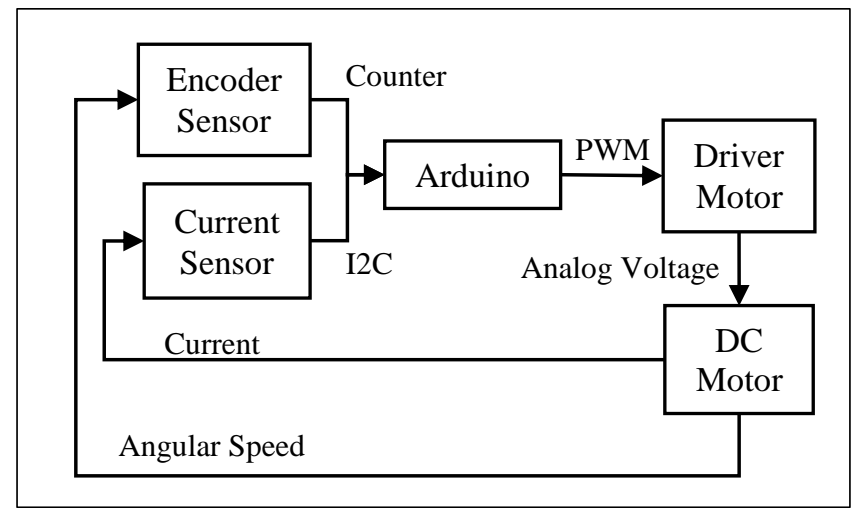

Fig. 2. System Block Structure Diagram

There are some types of motor drivers such as L298, BTS7960, and H-Bridge IRF. For the best result, BTS7960 and H-Bridge are recommended. The Arduino gives a control signal to the motor driver using Pulse Width Modulation (PWM). The motor power supply voltage is $24 \mathrm{~V}$. The DC Motor used is PG28 with the encoder sensor included. The 
encoder sensor has a 3.3volt supply; thus, it needs a buck converter. The current sensor used is INA219 with I2C communication. There are other electrical current sensors, such as ACS712, but they cannot read the electrical current well, especially if there is an electrical current surge.

\section{RESULT AND DISCUSSION}

\section{A. Simulink Matlab Simulation}

The section is about DC motor simulation in the Simulink Matlab. The parameter of the DC motor is as follows. The moment of inertia $(J)$ is $0.01 \mathrm{kgm}^{\wedge} 2$, the motor friction $(b)$ is $0.1 \mathrm{Nms}$, the EMF constant $(K)$ is $0.01 \mathrm{~V} / \mathrm{rad} / \mathrm{s}$, the motor torque constant $(K)$ is $0.01 \mathrm{Nm} / \mathrm{Amp}$, the resistance $(R)$ is $1 \mathrm{Ohm}$, and the inductance $(L)$ is $0.5 \mathrm{H}$.

The state-space model of DC motor is

$$
\begin{gathered}
\dot{x}=\left[\begin{array}{cc}
-10 & 1 \\
-0.02 & -2
\end{array}\right] x+\left[\begin{array}{l}
0 \\
2
\end{array}\right] u \\
y=\left[\begin{array}{ll}
1 & 0
\end{array}\right] x
\end{gathered}
$$

The response system result using the parameter controller in Table 1 is shown in Figure 3. The $\mathrm{x}$-axis is time in seconds, and the $y$-axis is the angular speed in radian per minute (RPM). The system's response performances listed in Table I are rise time, settling time, and overshoot.

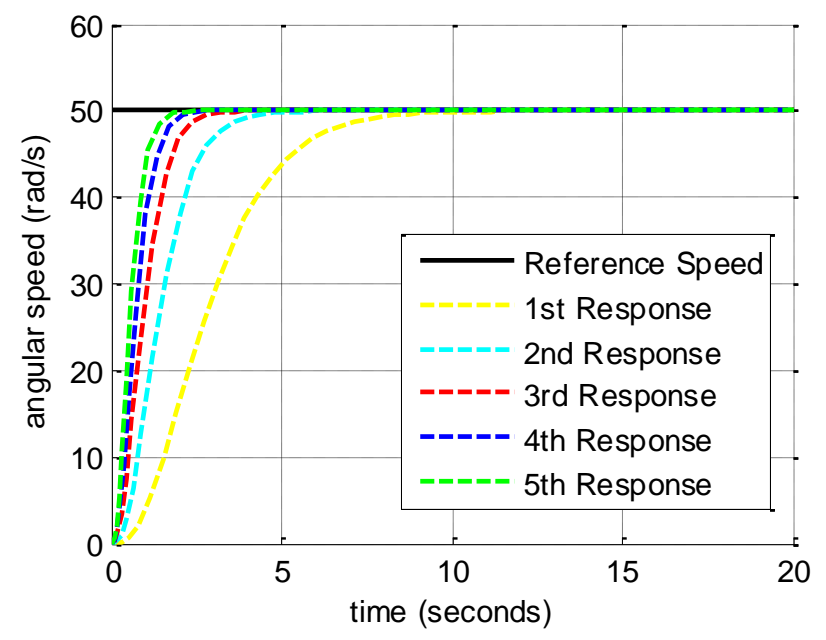

Fig. 3. Simulation results with various poles.

\begin{tabular}{|c|c|c|c|c|c|}
\hline \multirow[b]{2}{*}{ Pole } & \multicolumn{2}{|l|}{ Gain } & \multicolumn{3}{|c|}{ System Response } \\
\hline & $K=\left[\begin{array}{ll}k_{1} & k_{2}\end{array}\right]$ & $k_{I}$ & $\begin{array}{l}\text { rise } \\
\text { time }\end{array}$ & $\begin{array}{c}\text { settling } \\
\text { time }\end{array}$ & $\begin{array}{l}\text { over- } \\
\text { shoot }\end{array}$ \\
\hline$\left[\begin{array}{lll}-1 & -1 & -1\end{array}\right]$ & {$\left[\begin{array}{ll}36.49 & -4.5\end{array}\right]$} & -0.5 & 4.2372 & 7.5181 & 0 \\
\hline$\left[\begin{array}{lll}-2 & -2 & -2\end{array}\right]$ & {$\left[\begin{array}{ll}25.99 & -3\end{array}\right]$} & -4 & 2.1397 & 3.7866 & 0 \\
\hline$\left[\begin{array}{lll}-3 & -3 & -3\end{array}\right]$ & {$\left[\begin{array}{ll}18.49 & -1.5\end{array}\right]$} & -13.5 & 1.4489 & 2.5426 & 0 \\
\hline$\left[\begin{array}{lll}-4 & -4 & -4\end{array}\right]$ & {$\left[\begin{array}{ll}13.99 & 0\end{array}\right]$} & -32 & 1.0651 & 1.9354 & 0 \\
\hline$\left[\begin{array}{lll}-5 & -5 & -5\end{array}\right]$ & {$[12.49$ 1.5] } & -62.5 & 0.8552 & 1.5635 & 0 \\
\hline
\end{tabular}

TABLE I. POLE Placement

In Figure 3, the reference signal or setpoint used is 50 $\mathrm{rad} / \mathrm{s}$. It can be seen that the proposed controller can control the DC motor to reach the reference signal. The rise time is
0.8488 second, the settling time is 1.5056 second, and the overshoot is $0 \%$.

\section{B. Hardware Implementation}

The section is about hardware implementation using Arduino Uno. The system configuration setup is shown in Figure 4. The DC motor, current sensor, Arduino Uno R3, and motor driver can also be seen.

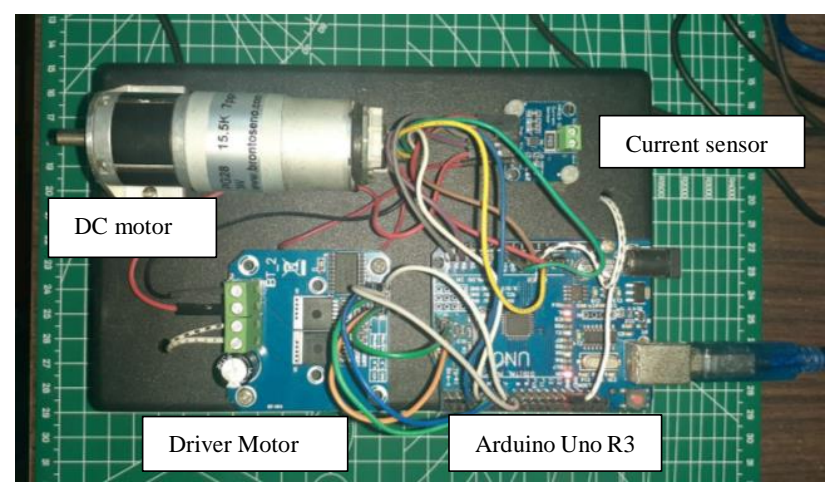

Fig. 4. Hardware implementation setup configuration.

The first experiment is to examine the effect of the integral control parameter $\left(k_{I}\right)$ addition. The response system result using the parameter in Table II is shown in Figure 5.

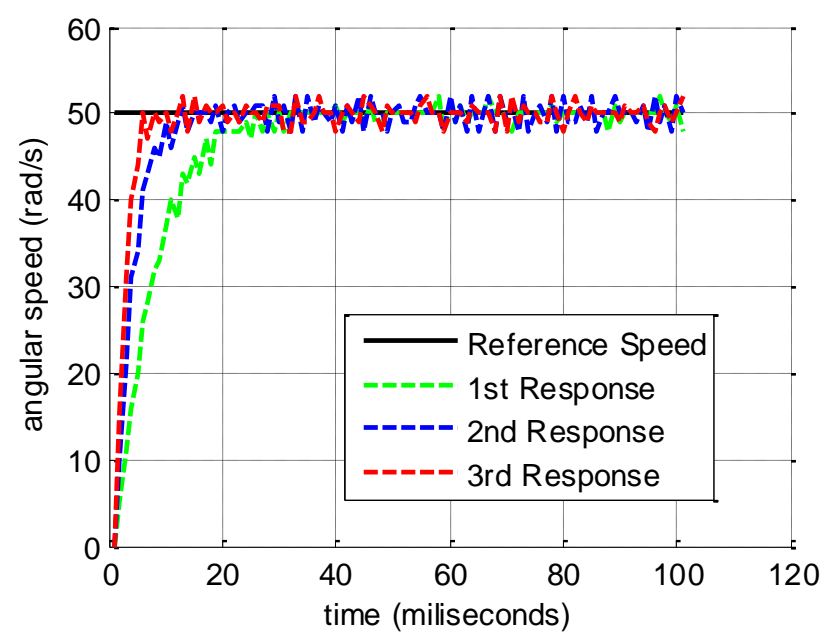

Fig. 5. System's response with various integral control parameters.

TABLE II.

\begin{tabular}{|c|c|c|c|c|}
\hline \multicolumn{2}{|c|}{ Table Column Head } & \multicolumn{3}{|c|}{ Response Systems } \\
\hline$K=\left[\begin{array}{ll}k_{1} & k_{2}\end{array}\right]$ & $\boldsymbol{k}_{I}$ & $\begin{array}{l}\text { rise } \\
\text { time }\end{array}$ & $\begin{array}{c}\text { settling } \\
\text { time }\end{array}$ & Overshoot \\
\hline$\left[\begin{array}{ll}0 & 0\end{array}\right]$ & 0.2 & 13 & 43 & 4 \\
\hline$\left[\begin{array}{ll}0 & 0\end{array}\right]$ & 0.4 & 6.1667 & 45 & 4 \\
\hline$\left[\begin{array}{ll}0 & 0\end{array}\right]$ & 0.6 & 3.8333 & 47 & 4 \\
\hline
\end{tabular}

CONTROLLER PARAMETER

Based on Figure 5 and Table II, it can be seen that the integral controller affects the rise time and settling time. The bigger integral controller parameter gives a faster rise time and settling time.

The second experiment is to examine the effect of the state feedback control parameter 
$K=\left[\begin{array}{ll}k_{1} & k_{2}\end{array}\right]$. The system responses using the controller parameter in Table III are shown in Figure 6.

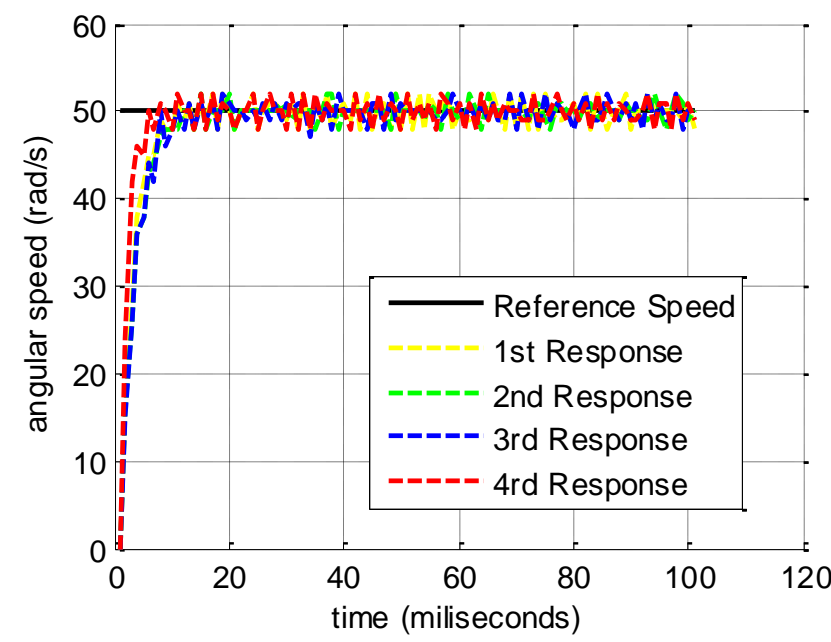

Fig. 6. System's response with various state feedback control parameters.

TABLE III.

CONTROLLER PARAMETER

\begin{tabular}{|c|c|c|c|c|}
\hline \multicolumn{2}{|c|}{ Controller Parameter } & \multicolumn{3}{|c|}{ Response Systems } \\
\hline $\boldsymbol{K}=\left[\begin{array}{ll}\boldsymbol{k}_{\mathbf{1}} & \boldsymbol{k}_{\mathbf{2}}\end{array}\right]$ & $\boldsymbol{k}_{\boldsymbol{I}}$ & $\begin{array}{c}\text { rise } \\
\text { time }\end{array}$ & $\begin{array}{c}\text { settling } \\
\text { time }\end{array}$ & Overshoot \\
\hline$\left[\begin{array}{ll}0.2 & 0\end{array}\right]$ & 0.6 & 4.6875 & 45 & 4 \\
\hline$\left[\begin{array}{ll}0.4 & 0\end{array}\right]$ & 0.6 & 6.0208 & 47 & 4 \\
\hline$\left[\begin{array}{ll}0.4 & 0.2\end{array}\right]$ & 0.6 & 6.0417 & 46 & 4 \\
\hline$\left[\begin{array}{ll}0.4 & 0.2\end{array}\right]$ & 1 & 2.5417 & 45 & 4 \\
\hline
\end{tabular}

Based on Figure 6 and Table III, it can be seen that the state feedback controller affects the rise time and settling time. The bigger state feedback controller parameter gives a faster rise time and settling time.

\section{Tracking Control}

In the section, the integral state feedback will be applied with various references. The result is shown in Figure 7. Setpoints (SP) used are 50RPM, 100RPM, and 150 RPM.

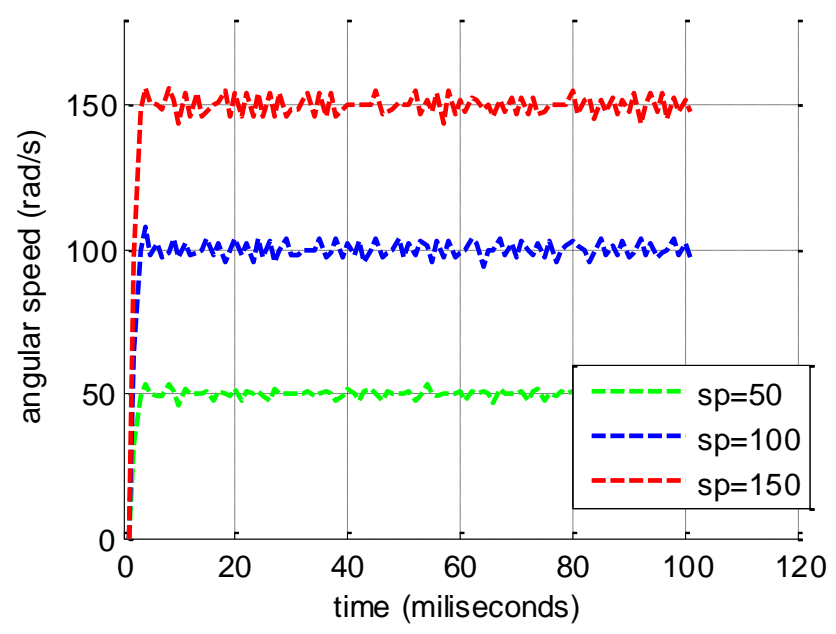

Fig. 7. Tracking control experiment result

Based on Figure 7, it can be seen that the integral state feedback can follow the reference (setpoint). The system performed with similar characteristics when various references are used. Overall, the system can give good performances with various references used. The integral state feedback has a robust characteristic because it always gives the same performances with different setpoints.

\section{Comparison with PID Controller}

In the section, the integral state feedback (ISF) will be compared with PID Controller [58][59][60][61][62][63][64] [65][66]. The result is shown in Figure 8. Setpoints or references used are 50RPM and 100RPM.

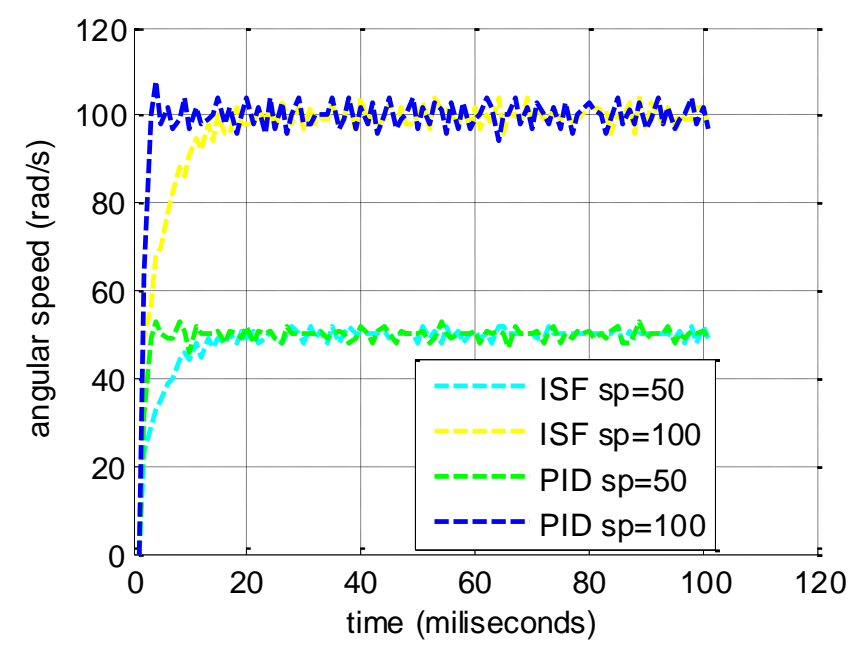

Fig. 8. Tracking control experiment. Integral state feedback results are compared with PID controller.

Based on Figure 8, the integral state feedback has a better system response than PID Controller. Visually, the time to reach the reference is faster than PID Controller.

\section{CONCLUSIONS AND FUTURE WORK}

The research is about controlling DC Motor using integral state feedback. The research was done by simulation and hardware implementation. In the simulation and hardware implementation result, the integral state feedback gave a good performance while reaching the set point. From the tracking control result with different setpoints, integral state feedback presented similar performance: the augmented system performed with fast rising time and settling time with small overshoot. Compared with the PID controller, the integral state feedback had a better system response in tracking control at some setpoints.

Future works of the research are widely open in many areas. The tuning parameter was still done using trial and error. Thus it will need a method to determine the parameter controller. An experiment with uncertainty and disturbance has not been done yet. Another challenging problem in applying the integral state feedback is that all states must be known. Hence, observers, such as minimum or full order observers, can be applied to overcome this issue in the future. The observer makes the augmented system will not need all states to be known. Another possible future research is to apply the Kalman filter to minimize the oscillation and noises in the output sensor. From a hardware perspective, it is also possible to conduct future research on controlling the DC motor's angular speed using the current sensor since it has 
more stability while reading the measurement than using the encoder sensor.

\section{ACKNOWLEDGMENT}

Authors would like to thank the editor and reviewer for their suggestions, comments, and advice to improve the paper quality.

\section{REFERENCES}

[1] J. Chotai and K. Narwekar, "Modelling and position control of brushed DC motor," in International Conference on Advances in Computing, Communication and Control 2017, ICAC3 2017, 2018, vol. 2018-January, pp. 1-5.

[2] P. Kumar, S. Chatterjee, D. Shah, U. K. Saha, and S. Chatterjee, "On comparison of tuning method of FOPID controller for controlling field controlled DC servo motor," Cogent Engineering, vol. 4, no. 1, Jul. 2017.

[3] A. S. Shekhawat and Y. Rohilla, "Design and Control of Twowheeled Self-Balancing Robot using Arduino," in Proceedings International Conference on Smart Electronics and Communication, ICOSEC 2020, 2020, pp. 1025-1030.

[4] S. Shekhar, P. K. Saha, and P. R. Thakura, "Optimal pid tuning of bldc drive using lqr technique," in Proceedings - 2019 IEEE International Conference on Intelligent Systems and Green Technology, ICISGT 2019, 2019, pp. 57-61.

[5] C. F. Hsu, C. T. Su, W. F. Kao, and B. K. Lee, "Vision-Based LineFollowing Control of a Two-Wheel Self-Balancing Robot," in Proceedings - International Conference on Machine Learning and Cybernetics, 2018, vol. 1, pp. 319-324.

[6] H. S. Juang and K. Y. Lurrr, "Design and control of a two-wheel selfbalancing robot using the arduino microcontroller board," in IEEE International Conference on Control and Automation, ICCA, 2013, pp. 634-639.

[7] S. Tayal, H. P. G. Rao, S. Bhardwaj, and H. Aggarwal, "Line Follower Robot: Design and Hardware Application," in ICRITO 2020 - IEEE 8th International Conference on Reliability, Infocom Technologies and Optimization (Trends and Future Directions), 2020, pp. 10-13.

[8] S. Saadatmand, S. Azizi, M. Kavousi, and D. Wunsch, "Autonomous Control of a Line Follower Robot Using a Q-Learning Controller," in 2020 10th Annual Computing and Communication Workshop and Conference, CCWC 2020, 2020, pp. 556-561.

[9] R. Covaci, G. Harja, and I. Nascu, "Autonomous Maze Solving Robot," in 2020 22nd IEEE International Conference on Automation, Quality and Testing, Robotics - THETA, AQTR 2020 - Proceedings, 2020.

[10] Y. Shao and J. Li, "Modeling and Switching Tracking Control for a Class of Cart-Pendulum Systems Driven by DC Motor," IEEE Access, vol. 8, pp. 44858-44866, 2020.

[11] V. M. Hernandez-Guzman, M. Antonio-Cruz, and R. Silva-Ortigoza, "Linear state feedback regulation of a furuta pendulum: Design based on differential flatness and root locus," IEEE Access, vol. 4, pp. 87218736, 2016.

[12] M. A. Hassanin, F. E. Abdel-Kader, S. I. Amer, and A. E. AbuMoubarka, "Operation of Brushless DC Motor to Drive the Electric Vehicle," in 2018 20th International Middle East Power Systems Conference, MEPCON 2018 - Proceedings, 2019, pp. 500-503.

[13] D. U. Thakar and R. A. Patel, "Comparison of Advance and Conventional Motors for Electric Vehicle Application," in 2019 3rd International Conference on Recent Developments in Control, Automation and Power Engineering, RDCAPE 2019, 2019, pp. 137142.

[14] W. J. Tang and S. Y. Cao, "A Fast Realization Method of Fuzzy PID Control for DC Motor," in Chinese Control Conference, CCC, 2018, vol. 2018-July, pp. 5131-5135.

[15] A. Jaya, E. Purwanto, M. B. Fauziah, F. D. Murdianto, G. Prabowo, and M. R. Rusli, "Design of PID-fuzzy for speed control of brushless DC motor in dynamic electric vehicle to improve steady-state performance," in Proceedings IES-ETA 2017 - International Electronics Symposium on Engineering Technology and Applications, 2017, vol. 2017-Decem, pp. 179-184.

[16] S. Zhang, W. Gu, Y. Hu, J. Du, and H. Chen, "Angular speed control of brushed DC motor using nonlinear method: Design and experiment," in Chinese Control Conference, CCC, 2016, vol. 2016Augus, pp. 1045-1050.

[17] M. A. Taut, G. Chindris, and D. Pitică, "PID Algorithm used for DC Motor Control," in 2018 IEEE 24th International Symposium for Design and Technology in Electronic Packaging, SIITME 2018 Proceedings, 2019, pp. 365-372.

[18] S. Chaouch et al., "DC-Motor Control Using Arduino-Uno Board for Wire-Feed System," in Proceedings of 2018 3rd International Conference on Electrical Sciences and Technologies in Maghreb, CISTEM 2018, 2019.

[19] G. Gasparesc, "PID control of a DC motor using Labview Interface for Embedded Platforms," in 2016 12th International Symposium on Electronics and Telecommunications, ISETC 2016 - Conference Proceedings, 2016, pp. 145-148.

[20] Z. Adel, A. A. Hamou, and S. Abdellatif, "Design of Real-Time PID tracking controller using Arduino Mega 2560for a permanent magnet DC motor under real disturbances.," in Proceedings of 2018 3rd International Conference on Electrical Sciences and Technologies in Maghreb, CISTEM 2018, 2019.

[21] Y. Guo and M. E. A. Mohamed, "Speed Control of Direct Current Motor Using ANFIS Based Hybrid P-I-D Configuration Controller," IEEE Access, vol. 8, pp. 125638-125647, 2020.

[22] B. Hekimoglu, "Optimal Tuning of Fractional Order PID Controller for DC Motor Speed Control via Chaotic Atom Search Optimization Algorithm," IEEE Access, vol. 7, pp. 38100-38114, 2019.

[23] Z. Tir, O. Malik, M. A. Hamida, H. Cherif, Y. Bekakra, and A. Kadrine, "Implementation of a fuzzy logic speed controller for a permanent magnet dc motor using a low-cost Arduino platform," in 2017 5th International Conference on Electrical Engineering Boumerdes, ICEE-B 2017, 2017, vol. 2017-January, pp. 1-4.

[24] Munadi, M. A. Akbar, T. Naniwa, and Y. Taniai, "Model Reference Adaptive Control for DC motor based on Simulink," in Proceedings 2016 6th International Annual Engineering Seminar, InAES 2016, 2017, pp. 101-106.

[25] M. Ahmad, A. Khan, M. A. Raza, and S. Ullah, "A study of state feedback controllers for pole placement," in 5th International MultiTopic ICT Conference: Technologies For Future Generations, IMTIC 2018 - Proceedings, 2018.

[26] D. Somwanshi, M. Bundele, G. Kumar, and G. Parashar, "Comparison of fuzzy-PID and PID controller for speed control of DC motor using LabVIEW," in Procedia Computer Science, 2019, vol. 152, pp. 252260.

[27] A. Varshney, D. Gupta, and B. Dwivedi, "Speed response of brushless DC motor using fuzzy PID controller under varying load condition," Journal of Electrical Systems and Information Technology, vol. 4, no. 2, pp. 310-321, Sep. 2017.

[28] A. Ma'arif, H. Nabila, Iswanto, and O. Wahyunggoro, "Application of Intelligent Search Algorithms in Proportional-Integral-Derivative Control of Direct-Current Motor System," in The 2019 Conference on Fundamental and Applied Science for Advanced Technology, 2019, vol. 1373 , no. 1, pp. 1-10.

[29] A. Apte, V. A. Joshi, H. Mehta, and R. Walambe, "DisturbanceObserver-Based Sensorless Control of PMSM Using Integral State Feedback Controller," IEEE Transactions on Power Electronics, vol. 35, no. 6, pp. 6082-6090, Jun. 2020.

[30] J. J. V. Sanjuan, R. J. M. Contreras, E. Y. Mendoza, J. L. Flores, R. O. Bravo, and M. E. Tlaxcaltecatl, "Design and Modeling of Integral Control State-feedback Controller for PMSM," in 2018 15th International Conference on Electrical Engineering, Computing Science and Automatic Control, CCE 2018, 2018.

[31] M. A. M. Cheema, J. E. Fletcher, D. Xiao, and M. F. Rahman, "A Linear Quadratic Regulator-Based Optimal Direct Thrust Force Control of Linear Permanent-Magnet Synchronous Motor," IEEE Transactions on Industrial Electronics, vol. 63, no. 5, pp. 2722-2733, 2016.

[32] D. H. Kim, T. H. Nguyen, P. S. Pratama, H. K. Kim, Y. S. Jung, and S. B. Kim, "Servo system design for speed control of AC induction motors using polynomial differential operator," International Journal of Control, Automation and Systems, vol. 15, no. 3, pp. 1207-1216, Jun. 2017.

[33] M. Hammouche, A. Mohand-Ousaid, P. Lutz, and M. Rakotondrabe, "Robust Interval Luenberger Observer-Based State Feedback Control: 
Application to a Multi-DOF Micropositioner," IEEE Transactions on Control Systems Technology, vol. 27, no. 6, pp. 2672-2679, 2019.

[34] P. Roy, B. Kar, A. Kumar, and B. K. Roy, "Level control of two tank system by fractional order integral state feedback controller tuned by PSO with experimental validation," in 2016 IEEE 1st International Conference on Control, Measurement and Instrumentation, CMI 2016, 2016, pp. 224-228.

[35] A. Samir, A. Hammad, A. Hafez, and H. Mansour, "Quadcopter Trajectory Tracking Control using State-Feedback Control with Integral Action," International Journal of Computer Applications, vol. 168, no. 9, pp. 1-7, Jun. 2017.

[36] M. Hypiusova, D. Rosinova, and A. Kozakova, "Comparison of State Feedback Controllers for the Magnetic Levitation System," in 2020 Cybernetics \& Informatics (K\&I), 2020, pp. 1-6.

[37] I. Iswanto and A. Maarif, "Robust Integral State Feedback Using Coefficient Diagram in Magnetic Levitation System," IEEE Access, vol. 8, pp. 57003-57011, Mar. 2020.

[38] Z. R. Labidi, H. Schulte, and A. Mami, "A Systematic Controller Design for a Photovoltaic Generator with Boost Converter Using Integral State Feedback Control," Engineering, Technology \& Applied Science Research, vol. 9, no. 2, pp. 4030-4036, Apr. 2019.

[39] K. G. Shankar, D. Jena, and R. Reddivari, "Comparative Overview of Internal Model Control Based PID, State Feedback Integral, and Sliding Mode Controllers for Buck Converter," in 2019 IEEE International Conference on Distributed Computing, VLSI, Electrical Circuits and Robotics, DISCOVER 2019 - Proceedings, 2019.

[40] S. Abdelmalek, A. Dali, and M. Bettayeb, "An Improved Observerbased Integral State Feedback (OISF) Control Strategy of Flyback Converter for Photovoltaic Systems," in Proceedings of 2018 3rd International Conference on Electrical Sciences and Technologies in Maghreb, CISTEM 2018, 2019.

[41] S. M. Sousa, V. J. S. Leite, S. W. Fernandes, and I. R. H. Oliveira, "SEPIC DC/DC converter control by observed-state feedback," in 2019 IEEE 15th Brazilian Power Electronics Conference and 5th IEEE Southern Power Electronics Conference, COBEP/SPEC 2019, 2019.

[42] O. Saleem and K. Mahmood-Ul-Hasan, "Indirect Adaptive StateFeedback Control of Rotary Inverted Pendulum Using Self-Mutating Hyperbolic-Functions for Online Cost Variation," IEEE Access, vol. 8, pp. 91236-91247, 2020.

[43] M. Haemers, S. Derammelaere, C. M. Ionescu, K. Stockman, J. De Viaene, and F. Verbelen, "Proportional-Integral State-Feedback Controller Optimization for a Full-Car Active Suspension Setup using a Genetic Algorithm," IFAC-PapersOnLine, vol. 51, no. 4, pp. 1-6, Jan. 2018.

[44] C. Cui, K. Song, C. Zhu, Q. Zhang, Y. Liu, and S. Dong, "State Feedback Controller Design of Dynamic Wireless Power Transfer System," in 2018 IEEE PELS Workshop on Emerging Technologies: Wireless Power Transfer, Wow 2018, 2018.

[45] S. J. Yoon, N. B. Lai, and K. H. Kim, "A Systematic Controller Design for a Grid-Connected Inverter with LCL Filter Using a Discrete-Time Integral State Feedback Control and State Observer," Energies, vol. 11, no. 2, p. 437, Feb. 2018.

[46] K. S. Pawar, M. V. Palwe, S. B. Ellath, and S. Y. Sondkar, "Comparison of Performance of PID Controller and State Feedback Controller for Flow Control Loop," in Proceedings - 2018 4th International Conference on Computing, Communication Control and Automation, ICCUBEA 2018, 2018.

[47] K. K. Patri and S. Samanta, "State feedback with integral control for boost converter \& its microcontroller implementation," in 2018 IEEMA Engineer Infinite Conference, eTechNxT 2018, 2018, pp. 1-5.

[48] S. H. Hussein and M. A. A. Al-Rawe, "Real Time Speed Control of the DC Motor in LABVIEW," in 2020 7th International Conference on Electrical and Electronics Engineering, ICEEE 2020, 2020, pp. 137-141.

[49] W. J. Tang, Z. T. Liu, and Q. Wang, "DC motor speed control based on system identification and PID auto tuning," in Chinese Control Conference, 2017, pp. 6420-6423.

[50] L. Giuntini, "Full state feedback control of buck-type PWM rectifier," in 2019 21st European Conference on Power Electronics and Applications, EPE 2019 ECCE Europe, 2019.
[51] D. M. Soares, H. A. M. Calil, and R. M. Stephan, "Cascade Control vs Full-State Feedback," in 2019 IEEE 15th Brazilian Power Electronics Conference and 5th IEEE Southern Power Electronics Conference, COBEP/SPEC 2019, 2019.

[52] E. Asa and Y. Yamamoto, "CDM based Controller design for Stabilizing the Altitude and Heading of an Aircraft," in Proceedings of the IEEE 2019 9th International Conference on Cybernetics and Intelligent Systems and Robotics, Automation and Mechatronics, CIS and RAM 2019, 2019, pp. 119-123.

[53] E. Asa, Y. Yamamoto, and T. Benjanarasuth, "Aircraft Altitude Control Based on CDM," in 2019 IEEE 2nd International Conference on Information and Computer Technologies, ICICT 2019, 2019, pp. 266-269.

[54] E. Asa and Y. Yamamoto, "Aircraft Heading Hold Control Based on CDM," in International Conference on Control, Automation and Systems, 2019, vol. 2019-October, pp. 247-250.

[55] T. H. Nguyen, D. H. Kim, S. J. Oh, H. K. Kim, and S. B. Kim, "Controller design for MIMO servo system using polynomial differential operator - A solution for increasing speed of an induction conveyor system," in Lecture Notes in Electrical Engineering, 2017, vol. 415 LNEE, pp. 529-542.

[56] D. H. Kim et al., "Application of servo controller design for speed control of AC induction motors using polynomial differential operator," in Lecture Notes in Electrical Engineering, 2016, vol. 371, pp. 337-352.

[57] S. B. Kim et al., "MIMO robust servo controller design based on internal model principle using polynomial differential operator," in Lecture Notes in Electrical Engineering, 2016, vol. 371, pp. 469-484.

[58] A. Ma'arif, Iswanto, N. M. Raharja, P. Aditya Rosyady, A. R. Cahya Baswara, and A. Anggari Nuryono, "Control of DC Motor Using Proportional Integral Derivative (PID): Arduino Hardware Implementation," in 2020 2nd International Conference on Industrial Electrical and Electronics (ICIEE), 2020, pp. 74-78.

[59] Iswanto, A. Ma'arif, R. D. Puriyanto, N. M. Raharja, and S. N. Rahmadhia, "Arduino Embedded Control System of DC Motor Using Proportional Integral Derivative," International Journal of Control and Automation, vol. 13, no. 4, pp. 658-667, 2020.

[60] L. Angel, J. Viola, and M. Vega, "Hardware in the loop experimental validation of PID controllers tuned by genetic algorithms," in 4th IEEE Colombian Conference on Automatic Control: Automatic Control as Key Support of Industrial Productivity, CCAC 2019 Proceedings, 2019.

[61] S. J. Hammoodi, K. S. Flayyih, and A. R. Hamad, "Design and implementation speed control system of DC motor based on PID control and matlab simulink," International Journal of Power Electronics and Drive Systems, vol. 11, no. 1, pp. 127-134, 2020.

[62] Y. Naung, A. Schagin, H. L. Oo, K. Z. Ye, and Z. M. Khaing, "Implementation of data driven control system of DC motor by using system identification process," in Proceedings of the 2018 IEEE Conference of Russian Young Researchers in Electrical and Electronic Engineering, ElConRus 2018, 2018, vol. 2018-Janua, pp. 1801-1804.

[63] R. K. Achanta and V. K. Pamula, "DC motor speed control using PID controller tuned by jaya optimization algorithm," in IEEE International Conference on Power, Control, Signals and Instrumentation Engineering, 2018, pp. 983-987.

[64] D. Maddi, A. Sheta, D. Davineni, and H. Al-Hiary, "Optimization of PID Controller Gain Using Evolutionary Algorithm and Swarm Intelligence," in 2019 10th International Conference on Information and Communication Systems, ICICS 2019, 2019, pp. 199-204.

[65] M. M. Maung, M. M. Latt, and C. M. Nwe, "DC Motor Angular Position Control using PID Controller with Friction Compensation," International Journal of Scientific and Research Publications (IJSRP), vol. 8, no. 11, pp. 149-155, 2018.

[66] S. A. Hamoodi, I. I. Sheet, and R. A. Mohammed, "A Comparison between PID controller and ANN controller for speed control of DC Motor," in 2nd International Conference on Electrical, Communication, Computer, Power and Control Engineering, ICECCPCE 2019, 2019, pp. 221-224. 